
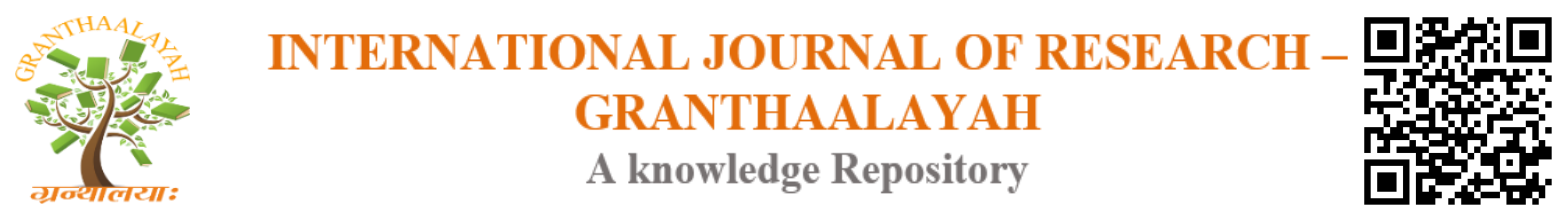

Science

\title{
COMPARATIVE STUDIES OF PHYSICAL AND COMBUSTION CHARACTERISTICS OF RICE HUSK BRIQUETTES PRODUCED USING DIFFERENT BINDING AGENTS
}

\author{
J. Sani ${ }^{1}$, T. Abubakar ${ }^{2}$, M. Mawoli ${ }^{1}$ \\ ${ }^{1}$ Sokoto Energy Research Center, Usmanu Danfodiyo University Sokoto \\ ${ }^{2}$ School of Remedial and Basic Studies, Department of Chemistry, Federal Polytechnic Kaura \\ Namoda
}

\begin{abstract}
Briquettes samples were manually produced using a hydraulic press from rice husk using starch and gum Arabic resin as binders. The proximate analysis of the samples reveals that the briquette produced using starch binder has the moisture value (9.26 \pm 0.251$)$, Ash (16.29 \pm 0.172$)$, Volatile matter (64.17 \pm 0.306$)$, and fixed carbon content of (9.55 \pm 0.502$)$ respectively whereas the gum

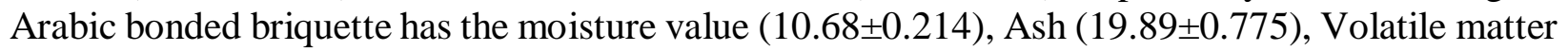
$(60.84 \pm 0.250)$, and fixed carbon content of $(8.26 \pm 0.535)$ respectively. The physical characteristics of the samples shows that the starch bonded briquette has the compressive strength of $(0.668 \pm$ $0.012 \mathrm{~N} / \mathrm{mm} 2)$, density $(0.68 \pm 0,028 \mathrm{~g} / \mathrm{cm} 3)$, ignition time $(0.17 \pm 0.01 \mathrm{~cm} / \mathrm{s})$, afterglow $(313 \pm 6.123$ $\mathrm{sec})$, and calorific value $(10.35 \pm 0.135 \mathrm{MJ} / \mathrm{Kg})$ respectively whereas the gum Arabic bonded briquette has the compressive strength of $(0.559 \pm 0.031 \mathrm{~N} / \mathrm{mm} 2)$, density $(0.575 \pm 0.031 \mathrm{~g} / \mathrm{cm} 3)$, ignition time $(0.13 \pm 0.007 \mathrm{~cm} / \mathrm{s})$, afterglow $(187 \pm 7.035 \mathrm{sec})$, and calorific value $(9.47 \pm 0.095$ $\mathrm{MJ} / \mathrm{Kg}$ ) respectively. Water boiling test shows that both the starch and gum Arabic bonded briquettes boil water to $1000 \mathrm{C}$ at 18 and 22 minutes respectively. The thermal efficiency of the briquettes during water boiling test shows that the starch bonded briquette has the highest thermal efficiency.
\end{abstract}

Keywords: Briquette; Calorific Value; Proximate Analysis; Starch; Binder.

Cite This Article: J. Sani, T. Abubakar, and M. Mawoli. (2019). "COMPARATIVE STUDIES OF PHYSICAL AND COMBUSTION CHARACTERISTICS OF RICE HUSK BRIQUETTES PRODUCED USING DIFFERENT BINDING AGENTS." International Journal of Research - Granthaalayah, 7(7), 183-190. https://doi.org/10.29121/granthaalayah.v7.i7.2019.746.

\section{Introduction}

Nearly half of the global human population used biomass on a daily basis for domestic cooking and heating. Similarly, in the next coming fifty years, woody biomass will still be the major energy source for the rural populace. Hence, there is a need to search for a more sustainable and environmentally friendly route for the utilization of the woody biomass. Rice, being the most 
popular food globally is associated with the generation of solid waste (husk) which, if properly harnessed and utilized, could be a better source of energy. Thus, briquetting of rice husk biomass to produce solid fuel for domestic heating, cooking and small industrial boilers would be a very crucial step in mitigating global warming and environmental pollution (Chou et al., 2009).

Converting rice husk into useful solid fuel briquettes is a welcome technology that would serve many purposes, which includes providing cheap energy and environmental pollution control by reducing wild dumping of rice husk by rice millers in the rice growing regions of the world. Similarly, fuel briquettes as an alternative energy will go a long way in reducing deforestation for firewood collection, thereby combating desertification and erosion (William and Mary, 2006).

Biomass Briquetting can be defined as the application of pressure to densify biomass materials into high mass ratio per volume for fuel purposes. Briquettes are distinguished from pellets by their size. Pellets typically have a length of 5 to $30 \mathrm{~mm}$, compared to briquettes which can range from $30 \mathrm{~mm}$ to $200 \mathrm{~mm}$ in diameter and are from $50 \mathrm{~mm}$ to $400 \mathrm{~mm}$ in length (Olorunnisola, 2004). Densification of rice husk into fuel briquettes transformed the bulk density of the material into highly dense solid fuel, depending on the compaction capacity of the machine; this has the advantages of easy handling and transportation and increased energy per volume. The relaxation behavior of the briquette depends on the type of biomass residue, until a limit in the reduction in briquette length is achieved, a dwell time of 20-40 seconds will produce a briquette with the smallest percentage relaxation possible, and the relaxed briquette length reduces with increasing dwell time, (Chin, 2000).

However, Briquette production from rice husk using molds and press Briquetting method required additional binder apart from water. The most commonly used binders include; clay, molasses, starch, cow dung, and resin to agglomerates the rice husk for better combustion. In this research, the aim is to compare the physical and combustion characteristics of rice husk briquettes produced using different binding agents; resin and cassava starch.

\section{Materials and Methods}

\subsection{Materials}

The rice husk Sample was collected from Kalanbaina Area, Sokoto. And the binders; resin and cassava starch were purchased from Sokoto central market, Sokoto, Sokoto State, Nigeria.

\subsection{Sample Preparation}

Domestic electric grinder/blender was used to crush the coarse particles of rice husk and the pulverized particles were separated with a $2 \mathrm{~cm}$ mesh, Water was added as a medium to facilitate the mixing which is a critical requirement for the cassava starch and gum Arabic. The prepared finer rice husk particles were mixed in 5:1 ratio for the two binders (cassava starch and gum Arabic) to make sample A and B respectively. 


\subsection{Briquette Production}

A fabricated hydraulic pressed operated manually to exert pressure on the substrates for briquettes production was used during briquette production. Metal mold pipe was filled with substrates and cover with iron disk. A metal fitted into the cylindrical mold was used in pushing out the formed briquette. The samples briquettes were produced at moderate pressure and ambient temperature. The briquette produced was then air dried for three weeks (Kyari, 2000).

\subsection{Proximate Analysis}

\subsubsection{Moisture Content}

The percentage moisture content of the briquette samples was determined based on sample weight measurement before and after oven drying. The initial weight of the sample was determined $\left(\mathrm{W}_{1}\right)$ and placed in an oven set at $105 \pm 3^{\circ} \mathrm{C}$ for 24 hours. The sample was removed and cooled in a desiccator and reweighed $\left(\mathrm{W}_{2}\right)$. Percentage moisture content was calculated according to procedure adopted by Adekunle et al., (2015) using equation 1.

Percentage moisture $=\mathrm{W} 1-\mathrm{W} 2 \times \frac{\mathrm{W} 100}{W_{1}}$

Where;

$\mathrm{W}_{1}=$ Weight of sample before oven drying (gram)

$\mathrm{W}_{2}=$ weight of oven dried sample (gram)

\subsubsection{Volatile Matter}

The briquette percentage volatile matter content was determined using Lenton furnace. The residue of dry sample from moisture content determination was heated at $300^{\circ} \mathrm{C}$ for complete elimination of volatiles, just before the materials turns to ashes, and then cooled in desiccator, based on the Adekunle, et. al., (2015) procedure, the crucible with known weight and its content was weighed and expressed as the percentage weight loss; the percentage volatile matter was computed using equation 2 .

$$
\text { Volatitle matter } \%=\frac{\text { Final weight }}{\text { Original weight }} \times 100
$$

\subsubsection{Fixed Carbon Content}

Fixed carbon was determined using the data previously obtained in the proximate analysis and according to Garcia et al., (2012) and was computed using equation 3

$$
\% \mathrm{FC}=100-(\% \text { Ash }+ \text { Volatile matter }+ \text { Moisture })
$$




\subsubsection{Ash Content}

Ash content of the samples briquettes was determined using furnace residue from fixed carbon determination. The sample was heated in a furnace at $590^{\circ} \mathrm{C}$, for two hours and transferred into a desiccator to cool down. The materials turned into white ash and weighed. The same procedure was repeated three times at $1 \mathrm{hr}$ interval until the weight was constant. The weight was recorded as the final weight of the ash, according to (ASTM, 1990). The percentage ash content was then calculated using equation 4.

$$
\text { Ash Content }=\frac{\text { weight of ash }}{\text { orinal weight of sample }} \times 100
$$

\subsection{Physical Characteristics Determination}

\subsubsection{Density}

Density as a physical property of the briquette is defined as structural packing of the molecules of the substance in a given volume. The density was determined using a weighing balanced in the laboratory by taking the weight of briquette sample and the dimension measurement using Vernier calliper according to ASTM (1990). The volume was evaluated using the relation $\mathrm{nr}^{2} \mathrm{~h}$ and the density was computed using equation 5 .

$$
\text { Density }=\frac{\text { mass }}{\text { volume }}
$$

\subsubsection{Compressive Strength}

Each sample of the rectangular briquette with dimension $3.0 \mathrm{~cm} \times 2.5 \mathrm{~cm}$ and thickness of $2.0 \mathrm{~cm}$ was loaded into the compression machine, and the shear load was determined and the load dial per division (R) was noted for every change in strain (AL). The stress (in $\mathrm{kN} / \mathrm{m}^{2}$ and \% strain was calculated using ASTM, (1990).

\subsection{Combustion Analysis}

\subsubsection{Calorific Value Determination}

The sample $(0.9 \mathrm{~g})$ was placed in a sample holder inside the bomb cylinder of the oxygen bomb calorimeter, which is the standard instruments for measuring calorific values of solid and liquid combustible samples. $10 \mathrm{~cm}$ fuse wire was measured and attached to each of the electrodes, oxygen gas was injected from the gas cylinder, the bomb cylinder was placed in a calorimeter bucket containing $2000 \mathrm{~g}$ of distilled water, the cover was set and the stirrer was first turned by hand to be sure that it runs freely before attaching drive belt (McCormick, 2009).

\subsubsection{Determination of Ignition Time}

This was determined as highlighted by Oladeji (2010). One piece of the briquette was grounded in centimetres and ignited using a Bunsen burner. The ignited briquette was allowed to burn until it 
extinguished itself. The flame propagation rate was estimated by dividing the distance burnt by the time taken in seconds.

\subsubsection{Combustibility Test Determination}

About $1 \mathrm{~kg}$ of each set of briquettes was stacked into an improved stove. It was lightened with a match after application of little absolute ethanol to initiate combustion. The fire was allowed to assume a steady combustion. Two litres of water in an aluminium pot whose initial temperature was recorded was placed on the stove and a stopwatch was initiated. A digital thermometer was inserted into the water inside the pot and readings taken after every two-minute interval and the corresponding temperatures recorded until water boiled (Onuegbu et al., 2011).

The time taken for each set of briquettes to boil two litres of water was recorded. (Etonihu et al., 2008).

\subsubsection{Afterglow Determination}

The afterglow was determined in order to estimate how long the individual briquettes will burn reducing before when they are used in cooking and heating. The procedure of Oladeji (2010) was used.

\section{Result and Discussion}

Table 1: proximate analysis of briquettes samples

\begin{tabular}{|l|l|l|l|l|}
\hline Samples & $\begin{array}{l}\text { Moisture content } \\
(\boldsymbol{\%})\end{array}$ & $\begin{array}{l}\text { Ash content } \\
(\boldsymbol{\%})\end{array}$ & $\begin{array}{l}\text { Volatile matter } \\
\text { content }(\boldsymbol{\%})\end{array}$ & $\begin{array}{l}\text { Fixed carbon } \\
\text { content (\%) }\end{array}$ \\
\hline Rc & $9.26 \pm 0.251$ & $16.29 \pm 0.172$ & $64.17 \pm 0.306$ & $9.55 \pm 0.502$ \\
\hline Rg & $10.68 \pm 0.214$ & $19.89 \pm 0.775$ & $60.84 \pm 0.250$ & $8.26 \pm 0.535$ \\
\hline
\end{tabular}

Note: values are the mean \pm standard deviation of the triplicates on each sample

$\mathrm{R}_{\mathrm{c}}=$ Starch binded briquette, $\quad \mathrm{R}_{\mathrm{g}}=$ Gum-Arabic binded briquette

\section{Proximate Analysis of Briquettes Samples}

The result of proximate analysis for the briquette samples (Table 1) showed that moisture content was $9.26 \%$ for Rc and $10.68 \% \mathrm{Rg}$. All the samples showed moisture content below $15 \%$. It is expected that moisture content of good fuels should be below $15 \%$. High moisture content negatively affects the fuel quality as it decreases system capacity and increases operational cost (Jauro, 2011).

Biomass typically has high volatile matter content (up to 80 per cent). However, for the rice husk briquette produced, a volatile content of $64.17 \%$ for $\mathrm{Rc}$ and $60.84 \%$ for $\mathrm{Rg}$ was recorded. This is high and signifies easy ignition of the briquette and Raw biomass contains high volatile matter of about $70-86 \%$, which makes it a highly reactive fuel, giving it a faster combustion rate, increase in flame length as suggested by Loo et al., (2008).

The high volatile matter content indicates that during combustion, most of the formed briquettes will volatilise and burn as gas in combustion chambers. The volatile matter would make the fuel 
smoky with a lot of pollutants during combustion. The utilization of biomass residues in their natural form as fuel is quite challenging due to their low bulk density, low heat release and the excessive amounts of smoke they generate (Amaya et al.,2007).

Ash, which is the inorganic matter left out after complete combustion of the biomass was found to be $16.29 \%$ and 19.89 for Rc and $\mathrm{Rg}$ respectively. This is the percentage of impurity that will not burn during and after combustion. The low ash content indicates that it is suitable for thermal utilisation. Higher ash content in a fuel usually leads to lower calorific value (Loo et al., 2008).

The fixed carbon of the fuel was $12.05 \%$ and $11.26 \%$ for $\mathrm{Rc}$ and $\mathrm{Rg}$ respectively. The fixed carbon is the most important thermal property of the fuel, and its value can be directly related to the heating/calorific value of the fuel. The percentage of the fixed carbon is important and it directly imparts on the calorific value. The decrease in the fixed carbon content can be attributed to the increased moisture content and volatile matter.

Table 2: Physical characteristics of briquette samples

\begin{tabular}{|l|l|l|}
\hline Samples & Compressive strength $\left(\mathbf{N} / \mathbf{m m}^{\mathbf{2}}\right)$ & Density $\left(\mathbf{g} / \mathbf{c m}^{\mathbf{3}}\right)$ \\
\hline Rc & $0.668 \pm 0.012$ & $0.68 \pm 0,028$ \\
\hline Rg & $0.559 \pm 0.031$ & $0.575 \pm 0.031$ \\
\hline
\end{tabular}

Note: values are the mean \pm standard deviation of the triplicates on each sample.

Table 3: Combustion analysis of briquette samples

\begin{tabular}{|l|l|l|l|}
\hline Samples & Ignition time $(\mathbf{c m} / \mathbf{s})$ & Afterglow $(\mathbf{s e c})$ & Calorific value $\mathbf{( M J} / \mathbf{K g})$ \\
\hline $\mathbf{R c}$ & $0.17 \pm 0.01$ & $313 \pm 6.123$ & $10.35 \pm 0.135$ \\
\hline $\mathbf{R g}$ & $0.13 \pm 0.007$ & $187 \pm 7.035$ & $9.47 \pm 0.095$ \\
\hline
\end{tabular}

Note: values are the mean \pm standard deviation of the triplicates on each sample

Table 4: Water boiling test of briquette samples

\begin{tabular}{|l|l|l|l|}
\hline Time & Rc & Rg & Charcoal \\
\hline $\mathbf{0}$ & 29.5 & 30.8 & 30.2 \\
\hline $\mathbf{2}$ & 33.9 & 32.5 & 36.0 \\
\hline $\mathbf{4}$ & 44.3 & 44.1 & 53.0 \\
\hline $\mathbf{6}$ & 52.8 & 54.9 & 60.0 \\
\hline $\mathbf{8}$ & 61.8 & 65.9 & 68.2 \\
\hline $\mathbf{1 0}$ & 69.0 & 76.2 & 74.6 \\
\hline $\mathbf{1 2}$ & 76.2 & 79.8 & 82.7 \\
\hline $\mathbf{1 4}$ & 89.7 & 86.1 & 92.4 \\
\hline $\mathbf{1 6}$ & 96.5 & 90.3 & 96.2 \\
\hline $\mathbf{1 8}$ & 100 & 94.7 & 100 \\
\hline $\mathbf{2 0}$ & & 97.2 & \\
\hline $\mathbf{2 2}$ & & 100 & \\
\hline
\end{tabular}

\section{Physical Characteristics and Calorific Value of Briquette Samples}

The densities and compressive strength of briquettes at a constant diameter and length varying with applied compression pressure are $0.668 \mathrm{~N} / \mathrm{mm}^{2}$ and $0.559 \mathrm{~N} / \mathrm{mm}^{2}$ for both $\mathrm{Rc}$ and $\mathrm{Rg}$ respectively. Briquette Rc has the highest density of $0.68 \mathrm{~g} / \mathrm{cm}^{3}$ and compressive strength of 0.668 
$\mathrm{N} / \mathrm{mm}^{2}$ while the briquette $\mathrm{Rg}$ has moderate density of $0.575 \mathrm{~g} / \mathrm{cm}^{3}$ and compressive strength of $0.559 \mathrm{~N} / \mathrm{mm}^{2}$. Calorific value results as shown on Table 3 indicated Rc has a calorific value of $10.35 \mathrm{MJ} / \mathrm{Kg}$ and $9.47 \mathrm{MJ} / \mathrm{Kg}$ for $\mathrm{Rg}$. The calorific value is influenced majorly by the fixed carbon content and volatile matter of the fuel. Rc had the highest fixed carbon content, hence its high calorific value. Calorific value of natural fuel can be estimated from its percentage carbon content together with other elements (Demirbas, 2000).

The combustion test on the fuel briquettes (Table 3) showed that the Ignition time of the briquettes $\mathrm{Rc}$ and $\mathrm{Rg}$ is $0.17 \mathrm{~cm} / \mathrm{sec}$ and $0.13 \mathrm{~cm} / \mathrm{sec}$ respectively. The result revealed that the higher the biomass content, the briquette, the lower its ignition time. A briquette with larger biomass content is generally expected to ignite faster. This is because of its higher volatile matter content, which consists of tars and other hydrocarbons that are combustible and have a low flash point. Since, a low ignition time briquette indicates safety concerns during storage, the risk of ignition and fire is increased in briquettes with low ignition time. Thus, caution must be taken to keep briquettes free from sparks and extreme heat.

The result of the afterglow time showed in table 3. The briquette Rc had the highest afterglow time of 313 seconds while Rg had low afterglow time 187 seconds. The afterglow time value can be attributed to factors like duration of initial combustion, adhesion between briquette particles and ventilation during and after combustion.

The thermal efficiency of the briquettes during water boiling test (Table 4). The Rc briquettes has the highest thermal efficiency by boiling 2 litter of water in 18 minutes same as does charcoal, while $\mathrm{Rg}$ briquette has the lowest thermal efficiency took 22 minutes to boil 2 litter of water. This indicates that the biomass briquette would be the best fuel for domestic cooking due to it safe utilization and environmental effect. This briquette would require the least quantity in kilogram to bring an amount of water to boil and evaporate.

\section{Conclusion}

The heating values of briquettes produced using rice husk biomass were high at the different binders. The calorific value was not inhibited by increase in starch levels at binary and tertiary combinations of briquettes from rice husk. The high volatile matter discharge from the briquettes could pose high health and climate risks when used in closed environments. The rice husk briquettes showed thermal behavior and physical and chemical characteristics similar to others biomass already used as fuel for energy generation. The high moderate heating value of 10.35 $\mathrm{MJ} / \mathrm{kg}$ and energy density of $0.68 \mathrm{~cm}^{3}$ for Rc while $9.47 \mathrm{MJ} / \mathrm{kg}$ and $0.575 \mathrm{~cm}^{3}$ for $\mathrm{Rg}$ provide a good combustibility of the briquettes. The maximum energy released was observed at $300^{\circ} \mathrm{C}$ for the briquettes. The time compression exerted little influence on the physical properties of the briquettes. The compaction of the wastes increases their energy density and reduces the problems associated with their disposal in the environment.

\section{References}

[1] Adekunle J.O, Ibrahim, J.S and Kucha, E.I (2015). Proximate and Ultimate Analysis of biocoal briquettes of nigeriasogboyaga and okaba sub-paummous coal. British journal of applied science and technology. (7) (1); pp. 114-123 www.sciencedomain.ogretrieved date 17-05-2017 
[2] Amaya, A., Medero, N., Tancredi, N., Silva, H. and Deiana, C. (2007). Activated Carbon Briquettes from Biomass Materials. Bioresour. Technol. 98(8), 1635-1641.

[3] ASTM (1990) Annual Book of ASTM Standards; Petroleum Products, Lubricants and Fossil Fuels Vol. 5 (Parts) Gaseous Fuels, Coal and Coke, D3173-87 pp 310-312

[4] Chin O. C and Siddiqui K. M, (2000). "Characteristics of some biomass briquettes prepared under modest die pressures," Biomass and Bioenergy, vol. 18, pp. 223-228. (Copyright@www.biocoalindia.com)

[5] Chou, C-S. Sheau-Hong, L., and Wen-Chung, L. (2009). Preparation and Characterization of Solid Biomass Fuel Made From Rice Straw and Rice Bran. Journal of Fuel Processing Technology. 90(1): 980-987.

[6] Demirbas A. (2000). "Physical properties of briquettes from waste paper and wheat straw mixtures," Energy Conversion and Management, vol. 40, pp. 437-445.

[7] Garcia P., Pizzaro C, Laulia A.V., and Bueno J.L, (2012), Characterization of Spanish biomass waste for energy use, bioresourcetechnol, 103, 249-258

[8] Jauro, A. (2011). Organic Geochemistry of Benue trough Coals: Biomarkers,

[9] Kyari, M.Z (2000) Briquetting of Corncob, unpublished M.sc thesis, submitted to the Chemistry

[10] program of Abubakar Tafawa Balewa University Bauchi, pp 31-35

[11] Loo S. V and Koppejan J, (2008). The Handbook of Biomass Combustion and Co-firing. Earthscan.

[12] McCormick, S.J (2009), Panr 1341Bomb Calorimeter Last update: August 11.

[13] Oladeji, J.T Fuel Characterization of Briquette produced from Corncob and Rice husk residue. The spec .J. scietech(2) (1); 101-106

[14] Olorunnisola A. O, (2004). "Briquetting of rattan furniture waste," Journal ofBamboo and Rattan, vol. 3, no. 2, pp. 139-149.

[15] Onuegbu, T.U, Ekpumola, U.E. I.M, Ekeoma, M.O and Obunselu, F.O (2011). Comparative studies of ignition time and water boiling test of coal and biomass briquette blend. IJRRAS 7 (2); 153-159 www.arpapress.com/volume/vol7 issue 2/IJRRAS. Retrieved date; 24:05:2017.

[16] William, P. C. and Mary, A. C., (2006). Principle of Environmental Science, Iniquity and Applications. 3rdedition. 296-298

*Corresponding author.

E-mail address: jamilu.sani@ udusok.edu.ng 